\title{
MARFAN'S SYNDROME*
}

\section{A REVIEW OF FOURTEEN CASES}

\author{
BY \\ J. M. PAHWA AND D. P. GUPTA \\ Sitapur, India
}

THE syndrome first described by Marfan (1896) is not a common condition, only 350 cases having so far been reported. Marfan noted the skeletal abnormalities in a $5 \frac{1}{2}$-year-old girl and called the condition dolicho-stenomelia; he described the fingers and toes as spider-like, but did not mention any ocular anomaly.

The clinical features of the syndrome, as at present understood, are as follows:

Skeletal Defects.-In most cases the skull is dolichocephalic. The limbs are exceedingly long and slender. There is not only a real increase in the length of the extremities as compared with those of normal children of the same age but a relative increase in comparison with the weight. The span between the tips of the middle fingers with arms extended often exceeds the height, and this is one of the typical aberrations.

The metacarpal bones and phalanges show an increase in length which in some cases is relatively greater in the terminal phalanges, giving to the fingers the delicate spider-like appearance described in Marfan's first case. The feet are also elongated because of the long and slender metatarsal bones and toes.

A funnel-shaped chest is quite common, but the pigeon-breasted type with narrowness and flattening of the chest wall is often seen. Some degree of kyphosis and scoliosis and laxity of the joints and ligaments, especially at the elbows, fingers, and knees, contribute to the usual appearance.

General Defects.-The muscular and subcutaneous tissue is poorly developed, giving an emaciated appearance which accentuates the already unnaturally long extremities. The face is prematurely aged, with a melancholic or pained expression. Many patients also have an abnormally high arched palate.

Cardiovascular Defects. - These have been summarized by McKusick (1955):

(1) Aorta

(i) Dilatation of aortic ring.

(ii) Dilatation of ascending aorta.

(iii) Dissecting aneurysms.

(iv) Combination of (i), (ii), and (iii).

(v) Coarctation.

(vi) Patent ductus arteriosus.

* Received for publication February 8, 1961. 
(2) Pulmonary Artery

(i) Dilatation.

(ii) Dissecting aneurysm.

(iii) Microscopic alteration of media.

(3) Septal Defects

(i) Atrial defect.

(ii) Fallot's tetralogy.

(4) Valvular Abnormalities

(i) Stretching and sacculation of the aortic cusps.

(ii) Other gross and microscopic changes.

(iii) Sub-acute bacterial endocarditis.

(5) DysRhythmias and Conduction Defects.

Ocular Defects.-The lenses are subluxated upwards and outwards, occasionally upwards and inwards, and rarely downwards and inwards. Iridodonesis, irregular anterior chamber, and miosis with feeble response to atropine are commonly met with. 60 per cent. of the patients are myopic according to Zentmayer (1936), and 90 per cent. according to Clarke (1939), who supposed that the myopia was not progressive. In individuals with pupils partly phakic and partly aphakic, uniocular diplopia or even bilateral quadrantanopia may be present. If the dislocated lens is beyond the pupillary area the symptoms are those of complete aphakia. Divergent or convergent strabismus and/or nystagmus are sometimes seen. Slit-lamp examination sometimes shows thinned out zonular fibres. The anterior surface of the iris is often smooth and may not show any crypts.

\section{Present Investigations}

Age and Sex.-The youngest patient examined in this series was $2 \frac{1}{2}$ years old and the oldest 70 years. Five were females and nine were males. The age distribution is set out in Table $\mathrm{I}$.

TABLE I

AGE DISTRIBUTION OF FOURTEEN PATIENTS

\begin{tabular}{c|c}
\hline Age Group (yrs) & No. of Cases \\
\hline $1-10$ & 4 \\
$11-20$ & 4 \\
$21-30$ & 2 \\
$31-40$ & 2 \\
$41-50$ & 1 \\
$51-70$ & 14 \\
\hline Total & 14 \\
\hline
\end{tabular}

Five cases of the complete and three of the incomplete syndrome were found in three generations of one family (Fig. 1, opposite).

Hereditary and Familial Incidence.-In four sporadic cases no family history was available, but the other ten cases were distributed in three families 
1

II

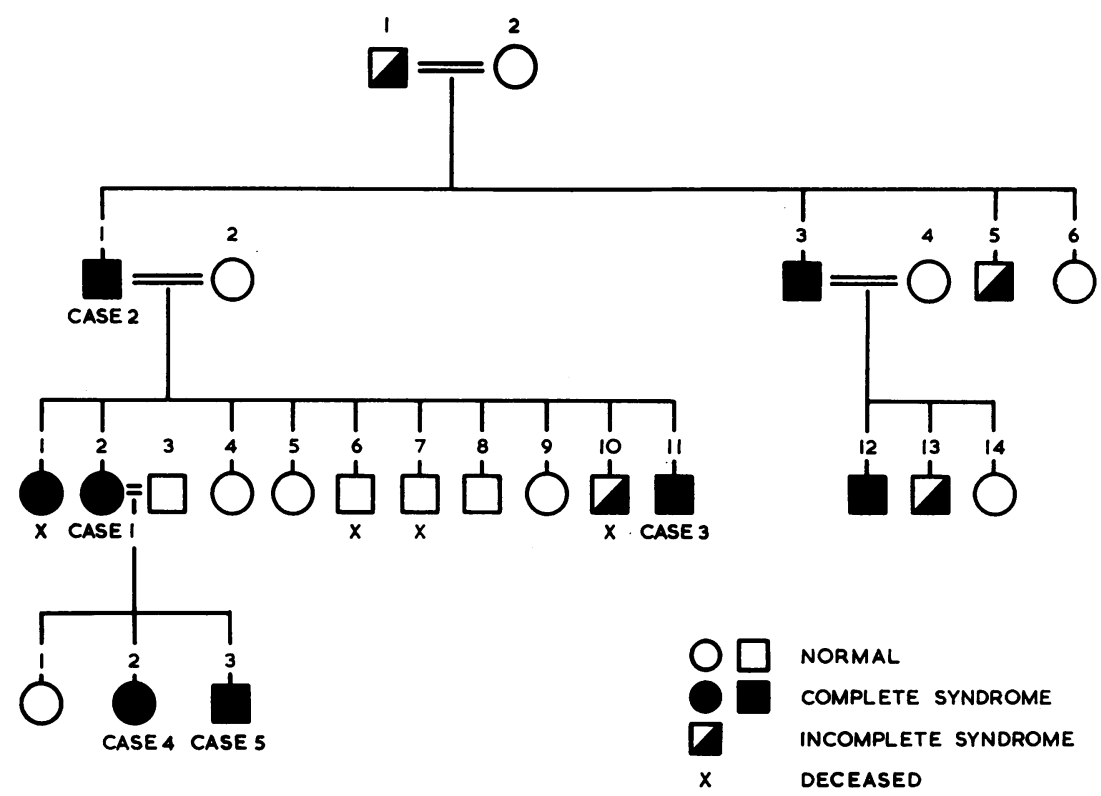

FIG. 1.-Genealogical tree of a family showing Marfan's syndrome seen in four generations. Only these marked cases $1,2,3,4$, and 5 were examined by us.

showing a definite heredity. Marfan's syndrome follows the Mendelian law with a dominant character (Lutman and Neel, 1949). In the literature the incidence in siblings is 30 per cent.

General Examination.-All the patients were tall, slim, and frail, with oblong faces. They had typical long spidery fingers, and the distance between the extended upper arms (measured from the tips of the middle finger) was more than the height. In two grown-up patients this excess was as much as 6 inches. Other features are listed in Table II.

TABLE II

SIGNS OF MARFAN'S SYNDROME IN FOURTEEN PATIENTS

\begin{tabular}{l|c}
\hline \multicolumn{1}{c|}{ Sign } & No. of Cases \\
\hline Funnel-shaped chest & 2 \\
Pigeon chest & 1 \\
Dolicocephalic head & 3 \\
Scoliosis & 3 \\
Divergent squint & 3 \\
Decreased subcutaneous fat and underdeveloped musculature & 13 \\
Prominent ears & 2 \\
Inguinal hernia & 1 \\
Mlue sclerae & 1 \\
\hline
\end{tabular}

Ophthalmological Examination.-The eyes appeared normal except in three cases in which divergent squint was obvious. In two patients of more 
than 40 years of age the lenses in both eyes were completely dislocated into the vitreous; one of these developed iritis and the other presented with secondary rise in ocular tension. A young boy of another family presented with spontaneous dislocation of the lens in one eye. In four eyes of three cases there was also an extensive retinal detachment.

In almost all cases the iris appeared lighter in colour and smoother, with absence of crypts, although radial streaks could be seen in some of them. Occasional deep clefts of darker colour concentric with the collarette were made out. Two cases showed signs of iritis with mild flare. The pupils were easily dilated except in the eyes with spontaneously dislocated lenses. In six cases the lens margin could be seen in the undilated pupillary area. The dislocation was found to be upwards and outwards in eight cases, upwards and inwards in two cases, and outwards in one case; in three cases (four eyes) the lens was completely dislocated.

Although high myopia is supposed to be common (Zentmayer, 1936; Clarke, 1939), it was of moderate degree in most of our patients, except one who showed $20 \mathrm{D}$ myopia, and most of them accepted an aphakic correction. Only four sporadic cases showed marked myopia with astigmatism. In one case no improvement could be obtained with any lens. The correction achieved with glasses was $6 / 24$ in myopic cases and $6 / 12$ or so in those which had an aphakic correction.

Cardiovascular Examination.-All the patients were examined in detail with $x$ rays of the chest, but an electrocardiogram was done in only five cases. There were only three cases in which the heart was normal. The cardiovascular abnormalities found are set out in Table III.

TABLE III

CARDIOVASCULAR ABNORMALITIES IN ELEVEN PATIENTS

\begin{tabular}{l|c}
\hline \multicolumn{1}{c|}{ Condition } & No. of Cases \\
\hline Cardiac enlargement & 2 \\
Tall and elongated aorta & 4 \\
Myocardial damage & 1 \\
Parasternal mid-diastolic murmur in second and third inter-costal & 2 \\
spaces with widely split second heart sound & 2 \\
Pre-systolic murmur in mitral area with mid-diastolic murmur & 1 \\
Aortic diastolic murmur & 1 \\
Lutembacher's syndrome & 1 \\
\hline
\end{tabular}

Only three patients showed obvious cardiac symptoms, i.e. breathlessness on exertion and occasional pain in the left side of the chest, particularly over the precordium, mostly on exertion but relieved by rest. There was no history of articular rheumatism except in one patient who gave a history of fever with joint pains, but showed no clinical evidence of rheumatic heart disease. 
One boy aged 11 years, showing all the features of Marfan's syndrome, had a collapsing pulse with an aortic diastolic murmur conducted down the left border of the sternum. Corrigan's and Durozier's signs were present. Screening showed enlargement of the left ventricle with prominence of the aorta, and the descending limb appeared further to the left. There was exaggerated pulsation of the left ventricle. The electrocardiogram showed a moderate degree of left ventricular preponderance and hypertrophy.

Another boy aged 8 years showed pigeon breast, Harrison's sulcus on both sides of the chest, and right inguinal hernia. His leg muscles were weak and he could not walk without the help of specially-made splinted shoes (Fig. 2). He had a mid-diastolic murmur with a widely-split second heart sound in the pulmonary area, a pre-systolic murmur with loud first heart sound, and a low-pitched rumbling soft mid-diastolic murmur in the mitral area. There was also a presystolic thrill in the mitral area. This patient had a double heart lesion, i.e. mitral stenosis and atrial septal defect with features of Lutembacher's syndrome. There was no history of rheumatic fever. An electrocardiogram indicated right ventricular hypertrophy, which was probably due to raised pulmonary vascular resistance, and the wave was suggestive of mitral stenosis.

FIG. 2.-A boy aged 8 years showing Marfan's syndrome with blue sclerae. Specially splinted shoes were worn as the leg muscles were very weak.

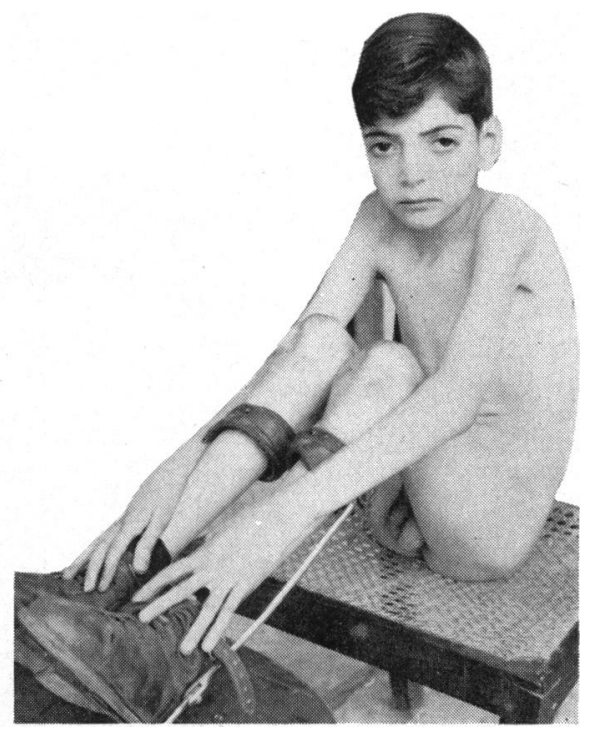

These symptoms with prominence of aortic knuckle and signs of incompetence were marked in the patients over 40 years of age.

Aortic involvement thus appears to be the most common significant feature of cardiac involvement.

Pathogenesis.-The basic cause of ectopia lentis and Marfan's syndrome is a matter of debate. The prevalent view is that the suspensory ligament is defective and the dislocation is secondary to changes in the zonule of Zinn. It is not certain whether the defect of the suspensory ligament is primary 
and ectodermal, or is due to a mesodermal defect which has impaired the development of the suspensory ligament. The occasional presence of pupillary membrane notches in the lens, correctopia, polycoria, etc., with ectopia lentis suggests that some mesodermal abnormality has hindered the growth of the suspensory ligament. As the anomaly is situated in the region of the foetal cleft, it is possible that this mesodermal tissue persists longer at this site. It is known that persistence of this mesodermal tissue produces imbalance of growth factors, not only in the suspensory ligament but also in other parts of the eye, and this, therefore, appears to be the primary factor. Weakness of the lower part of the suspensory ligament may permit an upward pull by the upper fibres of the ligament.

As the disease is hereditary and congenital, other anomalies are to be expected, and all may be traced to the defective development of the mesodermal tissues. These deformities include spinal curvature, arachnodactyly, cardiovascular lesions, and a light colour of iris with absence of crypts, etc. Kachele (1960) has noticed an association with "striae distensiae elasticae" on the skin, but no other ectodermal defect has been observed.

Weve (1931) thought that the mesoderm underwent a selective dystrophy with secondary involvement of the ectodermal tissue, and recommended the term "dystrophia mesodermalis hypoplastica" should be applied to Marfan's syndrome.

Mann (1957), however, said that the defect in the suspensory ligament might be primary and biochemical, and that the mesodermal defect might coexist, but might not be the essential cause of the defect in the ectodermal tissue. She suggested that a defect in the genes might operate on the mesodermal and ectodermal tissues at the same time, so that the anomaly might be genophytic.

Vogt (1931) suggested that the ciliary body might be responsible for the defective development of the suspensory ligament, but no such defect could be seen, and there appears to be no good reason why such a defect, if present, should always be localized in the lower part.

Ormond (1929) believed that some hormonal toxin produced biochemical effects, but did not try to put the blame on a primary ectodermal anomaly. Duke-Elder (1938) suggested that some organic biochemical poison acted on the embryonic mesoderm, and this is the view which we also hold.

Treatment.-As the disease is progressive and the lens may become more luxated or even completely dislocated forwards or backwards, either spontaneously or after a slight trauma such as may be produced by sneezing, coughing, or stooping, etc., and because this may lead to iridocyclitis or secondary glaucoma, early operative intervention is recommended. This is all the more necessary if the corrected visual acuity is low or if the shifting lens causes refractive changes. Moreover, a movable lens irritates the anterior surface of the vitreous and may cause degenerative changes in the 
choroid and retina thus predisposing to retinal detachment. The risk of glaucoma or retinal detachment after surgery in such cases is no greater than in unoperated cases. Three of our patients (four eyes) who were not operated on developed extensive retinal detachment.

Multiple discissions are traumautizing to the eye and may lead to iridocyclitis and retinal detachment.

These complications may be caused by an insufficient opening of the capsule (as the capsule is not tense so that after its rupture there is not much gaping), so that too little cortex is exposed to the dissolving action of the aqueous; this requires additional discission and traction on the ciliary body and ciliary processes. The method of extraction by diathermy has not been found satisfactory, and we recommend a technique which avoids unnecessary movement of the lens and permits a generous capsulotomy.

A prophylactic diathermic barrage by means of the Meyer-Schwickerath photo-coagulation apparatus is given one month before the operation if the lens is transparent, or soon after the operation if the lens is opaque. The generous capsulotomy is done by a two-needle method. In cutting the lens, downward movement is avoided to lessen the traction on the zonular fibres and ciliary body. The cut is made towards the needle which is being used as a spear, and then the second needle is used as a spear and the first is used for cutting. The lessened movement of the lens, besides reducing the traction on the ciliary body, also avoids unnecessary agitation of the vitreous, which may be already diseased. This method has been used in three cases with good results.

Loop extraction can be undertaken in adults, particularly in patients with cataractous lenses, but it is not recommended for children in whom vitreous loss may predispose to retinal detachment.

We agree with Kravitz (1959) in recommending early surgery, because the method described will not only permit the child to develop more normally but will also prevent the onset of later complications. Early discission is particularly necessary when the dislocated lens is causing visual difficulties.

\section{REFERENCES}

Clarke, C. C. (1939). Arch. Ophthal. (Chicago), $21,124$.

Duke-Elder, S. (1938). "Text-book of Ophthalmology", vol. 2, p. 1351. Kimpton, London. KaCHELE, G. E. (1960). A.M.A. Arch. Ophthal., 64, 135.

KRAVITZ, D. (1959). Ibid., 62, 764.

Lutman, F. C. and Neel, J. V. (1949). Arch. Ophthal. (Chicago), 41, 276.

MANN, I. (1957). "Developmental Abnormalities of the Eye", 2nd ed., p. 338. British Medical Association, London.

Marfan, A. B. (1896). Bull. Soc. méd. Hôp. Paris, 3 sér, 13, 220. (Quoted by Lutman and Neel, 1949).

McKusick, V. A. (1955). Circulation, 11, 321.

ORMOND, A. W. (1929). "XIII Concilium Ophthalmologicum, 1929. Hollandia", vol. 2, p. 645. (Quoted by Lutman and Neel, 1949).

VoGt, A. (1931). Klin. Mbl. Augenheilk., 87, 258.

Weve, H. J. M. (1931). Arch. Augenheilk. 104, 1.

Zentmayer, W. (1936). Arch. Ophthal. (Chicago), 15, 676. 